\title{
Atrophoderma Vermiculata Successfully Treated by 595 nm Dye Laser and Carbon Dioxide Laser
}

\author{
Hidetoshi Takahashi", Yoshio Hashimoto, Masuru Honma, Akemi Ishida-Yamamoto, Hajime Iizuka
}

Department of Dermatology, Asahikawa Medical University, Asahikawa, Japan.

Email: "ht@asahikawa-med.ac.jp

Received April 23 ${ }^{\text {rd }}, 2012$; revised May 26 ${ }^{\text {th }}, 2012$; accepted June $10^{\text {th }}, 2012$

\begin{abstract}
The treatment of atrophoderma vermiculatum is challenging. A 7-year-old girl had a unilateral atrophic skin lesion on her right cheek, which was diagnosed as unilateral atrophoderma vermiculata. She was treated by carbon dioxide and $595 \mathrm{~nm}$ pulsed dye laser and carbon dioxide laser. This resulted in prevention of the lesional progression with favorable cosmetic appearance of the skin.
\end{abstract}

Keywords: Atrophoderma Vermiculata; Dyed Laser; Carbon Dioxide Laser

\section{Introduction}

A 7-year-old Japanese girl had a 2-year history of atrophic skin lesion on her right cheek. She had been treated by a local dermatologist with topical corticosteroid without response. Examination showed grouped atrophic scars in a honeycomb pattern accompanied with slight erythema on her right cheek (Figure 1(a)). The patient had not suffered from any preceding skin lesion and was in good health. No family history was detected. Physical examination and laboratory investigations including blood analyses, liver and renal functions and urinalysis, were all within normal limits. The patient refused a biopsy.

We performed pulsed dye laser irradiation (V-Beam; Candela Corp, Wayland, MA, USA) at $595 \mathrm{~nm}$ with 1.5msec pulse-duration and at an energy fluence of $12 \mathrm{~J} / \mathrm{cm}^{2}$ using the $7 \mathrm{~mm}$ spot diameter. Although slight skin swelling was observed following the irradiation, edema was improved within $48 \mathrm{hr}$. After 3 months, we performed face resurfacing using a high-energy, pulsed carbon dioxide laser (NIDEK CO., LTD) at $300 \mathrm{~mJ}$ energy and $60 \mathrm{~W}$ power through $10 \mathrm{~mm}^{2}$ scanning hand piece and $30 \%$ density. The laser-irradiated skin showed pale pink erosion without bleeding and gentamycin ointment was applied until reepithelization was completed (7 days). Significant lesional improvement was observed after 6 months following the laser irradiation (Figure 1(b)).

\section{Discussion}

Atrophoderma vermiculatum is a rare, benign inflamma-

"Corresponding author. tory follicular atrophy that mainly affects cheeks of children. Clinical morphological hallmark is "worm-eaten" or "honey-combed" reticular atrophy. The pathogenesis is speculated as an abnormal keratinozatation of pilosebaceous units [1]. Atrophoderma vermiculatum usually affects both cheeks and only 3 cases of unilateral atrophoderma vermiculatum have been reported [2-4]. Hsu et $a l$. [2] reported a case associated with ipsilaretal cataract, alopecia, and a seizure. This suggests that some type of atrophoderma vermiculatum should be regarded as a neurocutaneous syndrome such as seen in epidermal nevus and nevus comedonicus.

The treatment of atrophoderma vermiculatun is challenging. Previous reports showed the effectiveness of systemic isotretinoin or topical tretionin [5-7]. Although isotretinoin is useful for atrophoderma vermiculatum, adverse effects such as hyperlipidemia, cheilitis, and premature epiphyseal closure limit its use. In contrast,

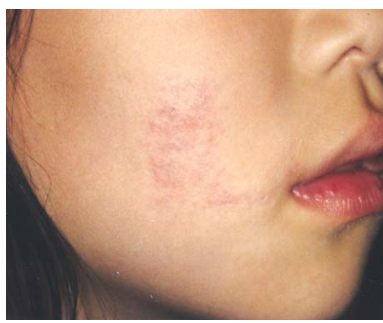

(a)

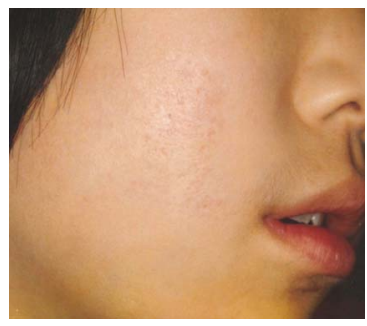

(b)
Figure 1. Clinical appearance of skin lesion before and after the laser irradiation. (a) Patients before the treatment: Grouped, honeycomb-patterned atrophic scar with erythema; (b) Improvement of the skin lesion following after the $595 \mathrm{~nm}$ dye laser and carbon dioxide laser. 
local laser treatment is less harmful and could be the first-choice treatment for the atrophoderma vermiculatum.

The usefulness of dye laser for inflammation such as psoriasis and scarred condition has been described [8-10]. Recently, pulsed dye laser and carbon dioxide laser have been successfully applied $[11,12]$. Previous reports showed that $585 \mathrm{~nm}$ dye laser, which is vascular-specific modality, was effective for atrophoderma vermiculatum. In our case, $595 \mathrm{~nm}$ dye laser was also effective for inflammatory atrophoderma vermiculatum. Dye laser with $595 \mathrm{~nm}$ is more penetrant and more potent than $585 \mathrm{~nm}$ dye laser and it was successfully applied for the atrophoderma vermiculatum. Furthermore, carbon dioxide laser was effective for the atrophic scar and our case confirmed its effect for the atrophoderma vermiculatum [12]. The mechanism is derived from both removal of fibrotic tissue and regeneration of collagen synthesis after its shrinkage [4]. Therefore, we speculate that the treatment using both dye laser and carbon dioxide laser is more useful than the treatment of either modality.

In conclusion, $595 \mathrm{~nm}$ pulsed dye laser and carbon dioxide laser were applied for a case of unilateral atrophoderma vermiculatum with favorable cosmetic response without adverse events.

\section{REFERENCES}

[1] D. R. Barron, A. L. Hirsch, L. Buchbinder and J. R. Promeranz, "Folliculitis Ulerythematosus Reticulata: A Case of Four Cases and Brief Review of the Literature," Pediatric Dermatology, Vol. 4, No. 2, 1987, pp. 85-89. doi:10.1111/j.1525-1470.1987.tb00757.x

[2] S. Hsu and A. Nikko, "Unilateral Atrophic Skin Lesion with Features of Atrophoderma Vermiculatum: A Variant of the Epidermal Nevus Syndrome?" Journal of the American Academy of Dermatology, Vol. 43, No. 2, 2000, pp. 310-312. doi:10.1067/mjd.2000.106514

[3] L. T. Rozum, A. H. Mehregan and S. A. M. Johnson, "Follicular Ulerythematosa Reciculata: A Case of Unilat- eral Lesions," Archives of Dermatology, Vol. 106, No. 3, 1972, pp. 388-389.

doi:10.1001/archderm.1972.01620120072020

[4] E. Arrieta and Y. Milgran-Sternberg, "Honeycomb Atrophy on the Right Cheek: Follicutitsi Ulerythematosa Reticulate (Atrophoderma Vermiculatum)," Archives of Dermatology, Vol. 18, 1988, p. 1101.

[5] Z. Apalla, G. Karakatsanis, M. Papageorgiou, C. Kastoridou and G. J. Chaidemenos, "A Case of Atrophoderma Vermiculatum Responding to Systemic Isotretioin," Case Reports in Dermatology, Vol. 4, No. 3, 2009, pp. 62-63.

[6] W. Weighthan, "A Case of Atrophoderma Vermiculatum Respomding to Isotretinoin," Clinical and Experimental Dermatology, Vol. 23, No. 2, 1998, pp. 89-91. doi:10.1046/j.1365-2230.1998.00326.x

[7] M. M. Nico, N. Y. Valente and M. N. Sotto, "Folliculitis Ulerythematosa Reticulata (Atrophoderma Vermculata): Early Detection of a Case with Unilateral Lesions," Pediatric Dermatology, Vol. 15, No. 4, 1998, pp. 285-286. doi:10.1046/j.1525-1470.1998.1998015285.x

[8] G. A. Katugampola, A. M. Rees and S. W. Lanigan, "Laser Treatment of Psoriasis," British Journal of Dermatology, Vol. 133, No. 6, 1995, pp. 909-913. doi:10.1111/j.1365-2133.1995.tb06924.X

[9] T. S. Alster and C. M. Williams, "Treatment of Keloid Sternotomy Scars with 585 nm Flashlamp-Pumped Pulsed Dye Laser," Lancet, Vol. 345, No. 8959, 1995, pp. 11981200. doi:10.1016/S0140-6736(95)91989-9

[10] S. Walia and T. S. Alster, "Prolonged Clinical Improvement of Atrophic Scar after $\mathrm{CO}_{2}$ Laser Resurfacing," Dermatologic Surgery, Vol. 25, No. 12, 1999, pp. 926930. doi:10.1046/j.1524-4725.1999.99115.x

[11] C. Handrick and T. S. Alster, "Laser Treatment of Atrophoderma Vermiculata," Journal of the American Academy of Dermatology, Vol. 44, No. 4, 2001, pp. 693-695. doi: $10.1067 / \mathrm{mjd} .2001 .112379$

[12] S. M. Clark, C. M. Mills and S. W. Lanigan, "Treatment of Keratosis Pilaris Atrophicans with the Pulsed Tunable Dye Laser," Journal of Cutaneous Laser Therapy, Vol. 2, No. 3, 2000, pp. 151-156. 